\title{
Comparison between The Effect of Sildenafil and Endometrial Scratch Injury on The Outcome (ICSI) Cycle
}

\author{
Mohamed Wafa ${ }^{1, *}$ MD., Emad Altemamy ${ }^{1}$ MD., Khaled Zakaria Elsheikha ${ }^{1}$ MD.
}

\author{
* Corresponding Author: \\ Mohamed Wafa \\ mohamedwafa343@gmail.com
}

Received for publication March 08, 2020; Accepted April 05, 2021; Published online April 05, 2021.

Copyright 2020 The Authors published by Al-Azhar University, Faculty of Medicine, Cairo, Egypt. All rights reserved. This an openaccess article distributed under the legal terms, where it is permissible to download and share the work provided it is properly cited. The work cannot be changed in any way or used commercially.

doi: 10.21608/aimj.2021.50056.1354

${ }^{1}$ Obstetrics and Gynecology Department, Faculty of Medicine, Al-Azhar University Cairo, Egypt.

Disclosure: The authors have no financial interest to declare in relation to the content of this article. The Article Processing Charge was paid for by the authors.

Authorship: All authors have a substantial contribution to the article.

\section{ABSTRACT}

Background: The study's main objective is to compare the effect of sildenafil therapy and endometrial scratch injury as methods for improving endometrial receptivity on the results of ICSI cycle.

Aim of the work: To compare the impacts of endometrial scratching and intravaginal sildenafil on endometrial receptivity in candidates with history of failed ICSI.

Patients and methods: A total of 150 patients with at least one prior failed ICSI cycle were involved in this prospective randomized controlled trial, which was done in private ICSI centers. These have been split into 3 groups; Control group $(n=50)$, endometrial scratch injury group $(n=50)$,and sildenafil group $(n=50)$. Endometrial scratch injury occurred on the 21st day of the spontaneous cycle before ICSI-ET treatment using a pipelle endometrium sampler. Received sildenafil citrate( $25 \mathrm{mg}$ tablets 3 times daily intravaginally) staring from the first day of FSH stimulation. Beta-HCG titer was used to diagnose pregnancy and was then verified by transvaginal ultrasound following 10-15 days of pregnancy.

Results: The difference in pregnancy rates among the control group and those who received endometrial scratch was statistically significant (P value 0.0405$)$ with a pregnancy rate of $56 \%(\mathrm{~N}=28)$ in comparison to the control group with $46 \%(\mathrm{~N}=23)$. However, with a pregnancy rate of $48 \%$ $(\mathrm{N}=24)$, there was no significant difference in the sildenafil group $\mathrm{P}$ value 0.067 . In the control group, all the pregnant patients showed positive fetal pulsations, while in the endometrial scratch group $92.8 \%$ showed positive fetal pulsations $(\mathrm{N}=26)$, and in the sildenafil group 95.8\% showed positive fetal pulsations ( $\mathrm{N}=23$ ).

Conclusion: Endometrial scratch injury was a safe and cheap method to improve pregnancy rate in ICSI cycles, however using it routinely needs more studies comparing it to other methods of improving endometrial receptivity.

Keywords: Sildenafil, Endometrial scratch, ICSI.

\section{INTRODUCTION}

The process of blastocyst implantation is complex; it involves interaction of variety of molecules. The receptivity of the endometrium affects blastocyst apposition and adhesion, as well as later trophoblast invasion. While steroid hormones (estrogen and progesterone) are known to control this process, the molecular basis of implantation is a major topic in the field. In vitro fertilization (IVF) cycles which lead in pregnancy, successful implantation is crucial and deemed the rate-limiting stage.

Various methods, such as endometrial scratch injury and sildenafil treatment, have been proposed in past years to enhance endometrial receptivity and implantation. To our knowledge, the literature does not agree about if endometrial injury raises the likelihood of pregnancy in women experiencing IVF cycles. According to one study, conducting endometrial scratch injury before an ICSI cycle resulted in a higher rate of live births $99^{1}$. In a yet another randomized controlled trial, researchers found no evidence that endometrial scratch injury has an effect on live birth rate in comparison to no intervention $^{2}$. The literature has also provided varying results when it comes to the exact timing of the endometrial scratch. The timing of endometrial injury in prior randomized control trials differed, with certain research conducting the injury among cycle days $4-7^{3}$, cycle days $16-23^{4}$, cycle days 21 $26^{5}$, or even executing the procedure twice in the same cycle ${ }^{6}$. Moreover, most research on endometrial injury undertakes the scratch during the luteal phase that prevents women from attempting pregnancy during the previous cycle. Despite improved research production over the last 15 years, there is a persistent lack of information about intervention.

Endometrial injury causes pain in the patient which can require a separate visit in addition to typical monitoring. The timing of endometrial scratch is examined in this research to see if there is a correlation between it and subsequent implantation.

Regarding the use of sildenafil citrate to enhance endometrium receptivity; there is growing evidence 
regarding the relation between uterine blood flow and endometrial response ${ }^{7}$.

In women with a history of repeated miscarriages vaginal sildenafil was found to minimize peripheral natural killer cell (NK-cell) activity and enhance pregnancy rates. While the mechanism of sildenafil's effect on natural killer cell activity is unknown, increased uterine artery flow appears to have a significant impact on the endometrial NK-cell population ${ }^{8}$.

In normal healthy populations, however, this drug has had adverse effects, including myocardial infarctions and strokes ${ }^{9,10}$.

The aim of this research was to compare the impacts of endometrial scratching and intravaginal sildenafil on endometrial receptivity in candidates with history of failed ICSI.

\section{PATIENTS AND METHODS}

From January 2017 to January 2019, a prospective randomized controlled study was performed in an IVF center. One hundred and fifty patients were enrolled in the research, the inclusion criteria being that they had at least one prior failed ICSI attempt and were good respondents with good quality embryos in those attempts. All patients with all kinds of fibroids or previous operations on the endometrium were removed from this research. Our sample was divided into 3 groups; Group A no intervention, Group B were endometrial scratch injury was done, and finally Group $\mathrm{C}$ with sildenafil therapy. In group B endometrial scratch injury occurred on the 21 day of the spontaneous cycle before ICSI-ET treatment using a pipelle endometrium sampler. Patients in group $\mathrm{C}$ received sildenafil citrate $25 \mathrm{mg}$ tablets 3 times daily intravaginally staring from the first day of FSH stimulation. Patients were randomly allocated to 3 groups during the IVF therapy cycle using a randomized block design to generate a random allocation sequence. Down regulation was started on the 21st day of the cycle preceding ovarian stimulation with injection of GnRH agonist daily, For pituitary down-regulation and endogenous gonadotropin depletion, patients were given 0.1 $\mathrm{mg}$ /day of the $\mathrm{GnRH}$ analogue (GnRH-a) buserelin acetate (Superfact),triptorelin acetate (Decapeptyl), or Leuprolide (Lupron). These patients were given 150-225 IU of hMG (Pergonal, Menogon, Menopure, or Gonal FI) daily to stimulate follicular growth after serum 17 E2 levels fell below 200 pmoI/L. The FSH/HMG dose was adjusted based on the patient's response.

On sonographic detection of at least two 18-mm leading follicles, 10,000 IU of hCG (Chorimon) were given to induce oocyte maturation, also the endometrium thickness is measured on this day.
And use a single lumen 17-gauge needle, oocytes were retrieved 32-36 hrs following hCG administration using guided vaginal sonography (Cook, Queensland, Australia). After fourteen days of luteal phase support, the patient was screened for pregnancy with beta-HCG titer, which was verified by transvaginal ultrasound after 10-15 days of pregnancy.

\section{Statistical Methods:}

Using the SPSS program statistical computer package version 12, the collected data was structured, tabulated, and statistically analyzed. The range, mean and standard deviations have been computed for the quantitative variables.

The student ( $\mathrm{t}$ ) test was used to statistically analyze the differences among the two means.

In order to test the relationship between the two variables, Pearson correlation coefficient $(r)$ was determined. The number and percent distributions for categorical variables were determined. As a significance test, the Chi square test was used, and if it was found to be ineffective, the Fisher exact test was used.

The significance level for interpreting the outcomes of significance tests was set at $\mathrm{p}<0.05$.

\section{RESULTS}

In our study we reviewed a total of 150 patients that were split among 3 groups. The base characteristics of our 3 research groups are shown in Table 1.There was no significant difference between the research groups regarding age, duration of infertility and body mass index (BMI). However, there was a significant difference among the groups regarding the endometrial thickness in both groups $\mathrm{B}$, and $\mathrm{C}$ compared to the control group ( $\mathrm{P}$ value 0.004 and 0.0037 respectively). A total of 23 patients (46\%) in the control group achieved clinical pregnancy, while in group B 28 patients were pregnant (56\%), and in group C 24 (48\%) were pregnant.

Comparing the control group with group $\mathrm{B}$, this revealed a significant difference regarding the 2 groups ( $p$ value 0.00401 ). The difference between the control group and group C, from the other hand, was not significant ( $p$ value 0.0671 ).

No statistically significant differences in the causes of infertility between groups. In table 5 . Comparison among the study groups regarding the number of previous IVF trials. In this aspect, there were no statistically significant differences among the groups. 


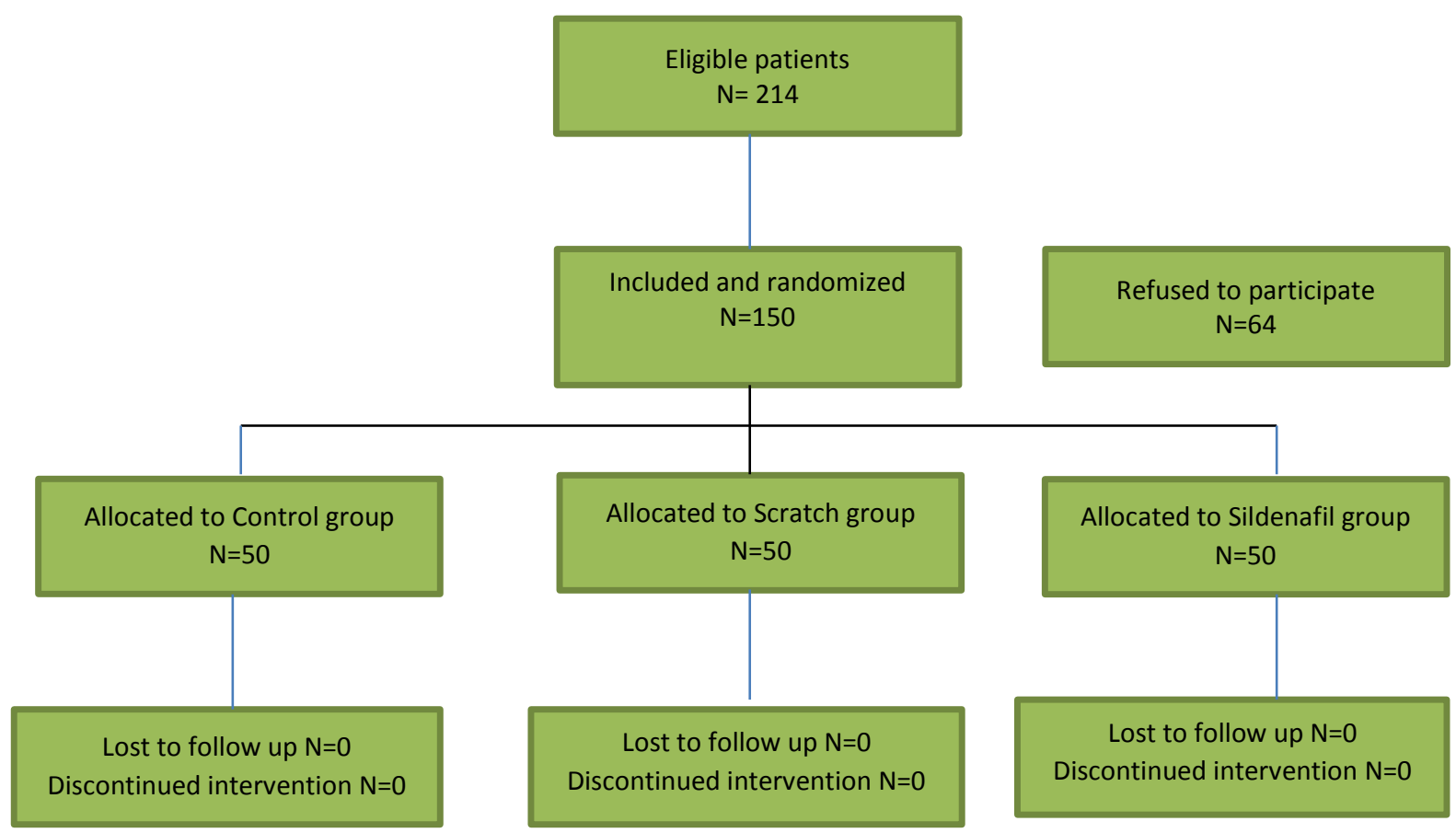

Fig.1: Flowchart of participants in this trial.

\section{DISCUSSION}

\begin{tabular}{|l|c|c|c|c|}
\hline Patient's & Control & $\begin{array}{c}\text { Endometrial } \\
\text { scratch }\end{array}$ & Sildenafil & P Value \\
\hline Age (Y)range & $20-41$ & $20-43$ & $21-39$ & 0.409 \\
\hline $\begin{array}{l}\text { Duration of } \\
\text { Infertility (Y), } \\
\text { range }\end{array}$ & $1-19$ & $1-17$ & $1-16$ & 0.781 \\
\hline $\begin{array}{l}\text { Average BMI } \\
\text { Average } \\
\text { endometrial } \\
\text { thickness } \\
\text { mm }\end{array}$ & 30.64 & 30.36 & 32.13 & 0.755 \\
\hline $\begin{array}{l}\text { Average } \\
\text { FSH (IU/L) }\end{array}$ & 4.57 & 10.88 & 10.9 & 0.003 \\
\hline $\begin{array}{l}\text { Average } \\
\text { LH (IU/L) }\end{array}$ & 6.66 & 5.56 & 8.47 & 0.530 \\
\hline
\end{tabular}

Table 1: Patient's characteristics and cycle related factors.

\begin{tabular}{|c|c|c|c|c|}
\hline \multicolumn{1}{|c|}{ Variable } & Control & $\begin{array}{c}\text { Endometrial } \\
\text { scratch }\end{array}$ & Sildenafil & $\begin{array}{c}\text { P } \\
\text { Value }\end{array}$ \\
\hline $\begin{array}{c}\text { Mean number of } \\
\text { collected oocytes }\end{array}$ & 18,63 & 20,2 & 19,14 & $\mathbf{0 , 5 1 6}$ \\
\hline $\begin{array}{l}\text { Embryos } \\
\text { transferred }\end{array}$ & 2,9 & 2,7 & 2,5 & $\mathbf{0 , 4 2 9}$ \\
\hline ET grade: & & & & \\
$\bullet \quad$ G1 & 1,10 & 1,34 & 1,31 & $\mathbf{0 , 0 7 2}$ \\
- G2 & 2,21 & 1,79 & 1,86 & $\mathbf{0 , 1 3 8}$ \\
- G3 & 0,96 & 0,93 & 0,97 & $\mathbf{0 , 1 2 7}$ \\
\hline
\end{tabular}

Table 2: Comparison of treatment cycle outcomes.

\begin{tabular}{|c|c|c|c|}
\hline Variable & Control & Endometrial scratch & Sildenafil \\
\hline \multirow{2}{*}{ Pregnancy rate } & $\mathrm{N}=\mathbf{2 3}$ & $\mathrm{N}=\mathbf{2 8 ( 5 6 \% )}$ & $\mathrm{N}=\mathbf{2 4 ( 4 8 \% 0 )}$ \\
& $\mathbf{( 4 6 \% )}$ & (P.value=0.0405) & (P.value=0.067) \\
\hline
\end{tabular}

Table 3: Comparison between both groups as regard pregnancy rate. 


\begin{tabular}{|c|c|c|c|c|c|c|}
\hline \multirow{2}{*}{$\begin{array}{c}\text { Cause Groups } \\
\text { of infertility }\end{array}$} & \multicolumn{2}{|c|}{ Control group } & \multicolumn{2}{c|}{ Scratch group } & \multicolumn{2}{c|}{ Sildenafil group } \\
\cline { 2 - 7 } & $\mathrm{N}$ & ${ }^{\prime} \mathrm{O}$ & $\mathrm{N}$ & ${ }^{\prime} \mathrm{O}$ & $\mathrm{N}$ & ' $^{\circ}$ \\
\hline Male factor & 23 & 46.70 & 13 & 26.70 & 18 & 36.00 \\
\hline Male -tubal factor & 0 & 0.00 & 5 & 10.00 & 2 & 4.00 \\
\hline Ovarian factor & 4 & 6.70 & 10 & 20.00 & 9 & 18.00 \\
\hline Endometriosis & 2 & 3.30 & 0 & 0.00 & 1 & 2.00 \\
\hline Tubal factor & 7 & 13.30 & 5 & 10.00 & 2 & 3.30 \\
\hline Tubal- ovarian factor & 0 & 0.00 & 2 & 3.30 & 3 & 6.00 \\
\hline Sex selection & 0 & 0.0 & 2 & 3.30 & 0 & 0.0 \\
\hline Unexplained & 8 & 16.70 & 10 & 20.0 & 7 & 14.0 \\
\hline Unknown & 6 & 13.30 & 3 & 6.70 & 8 & 16.70 \\
\hline Total & 50 & 100 & 50 & 100 & 50 & 100 \\
\hline P value & & & 0.229 & & 0.2 & \\
\hline
\end{tabular}

Table 4: Comparison between groups with regard to cause of infertility.

\begin{tabular}{|c|c|c|c|c|c|c|}
\hline \multirow{2}{*}{$\begin{array}{l}\text { Pervious } \\
\text { failures }\end{array}$} & \multicolumn{2}{|c|}{$\begin{array}{c}\text { Control } \\
\text { group }\end{array}$} & \multicolumn{2}{c|}{$\begin{array}{c}\text { Scratch } \\
\text { group }\end{array}$} & \multicolumn{2}{|c|}{$\begin{array}{c}\text { Sildenafil } \\
\text { group }\end{array}$} \\
\cline { 2 - 8 } & $\mathrm{N}$ & ${ }^{\prime} \mathrm{O}$ & $\mathrm{N}$ & '0 & $\mathrm{N}$ & $\%$ \\
\hline 1 & 40 & 80 & 38 & 76.0 & 41 & 82.0 \\
\hline 2 & 8 & 16 & 8 & 16.0 & 5 & 10.0 \\
\hline 3 & 1 & 2.0 & 3 & 6.0 & 4 & 8.0 \\
\hline 4 & 1 & 2.0 & 1 & 2.0 & $\#$ & 0.0 \\
\hline Total & 50 & 100.0 & 50 & 100.0 & 50 & 100.0 \\
\hline P value & \multicolumn{3}{|c|}{0.805} & \multicolumn{2}{|c|}{0.705} \\
\hline
\end{tabular}

Table 5: Comparison between both groups as regard number of pervious failures

\section{DISCUSSION}

The "rate-limiting step" in the success of in vitro fertilization (IVF) cycles is implantation ${ }^{11}$. In spite of multiple advancements in assisted reproduction technology (ART), pregnancy rates continues to be poor. ${ }^{12}$

IVF success rates have recently been recorded in terms of cumulative live birth rate (CLBR) per female in recent articles, offering a more reliable approximation which can be applied to individual couples. CLBR after IVF has been recorded to be between 45 and $55 \%$ in general. Preimplantation genetic diagnosis and increased maternal age have also been found to lower these rates substantially. ${ }^{13}$

Increased conception or fertilization rates, on the other hand, do not always mean increased pregnancy rates. About $30 \%$ of naturally conceived embryos die before implantation and more than $50 \%$ of IVF embryos fail to be implanted ${ }^{14}$

Implantation relies on endometrial - embryonic interaction and receptive endometrium is required for apposition, adhesion and blastocyst invasion ${ }^{15}$.

Several techniques for enhancing the endometrial receptivity and implantation rate in ART were proposed. In animals, scratching and endometrial trauma were shown to induce decidualization and endometrial receptivity ${ }^{16}$.

The current study suggests that endometrial local injury that used a biopsy catheter on day 21of the spontaneous monthly cycle before the IVF-ET treatment increases the rate of pregnancy between repeated implant failure patients receiving IVF/intracytoplasmic sperm injection: a randomized clinical study. On the other hand, the use of sildenafil doesn't seem to influence the rate of pregnancy.

The aim of this study was to discover a technique for improving endometrial receptivity and increase implantation rate in ART cycles.

The minimum distance among the echogenic interfaces of myometrium and endometrium, measured in the plane via the uterine body's central longitudinal axis, is referred to as endometrial thickness. In IVF - embryo transfer cycles, increased endometrial thickness is linked to a higher rate of pregnancy ${ }^{17}$.

Pregnancy cannot be accomplished if the endometrial thickness is less than a certain critical cut-off limit, according to data from donor oocyte programs. While studies have shown that the endometrium thickness required for successful implantation could be as thin as $4 \mathrm{~mm}^{18}$, in most instances, at least $6 \mathrm{~mm}$ of endometrial thickness is required ${ }^{19,20}$.

The existence of a thin endometrium had no impact on cumulative PRs in a prospective large cohort study ${ }^{21}$, especially whenever high-quality embryos were transported $^{17}$.Thin or hyperechogenic endometrium or persistent endometrial fluid impaired the result in tubal factor, but not in polycystic ovary syndrome (PCOS) ${ }^{21}$.

The result of this study showed statistically significant in the endometrial thickness among the control and the biopsy group $(\mathrm{p}<0.05)$. This is in agreement with Narvekar et al., ${ }^{23}$.

The results showed that the pregnancy rates between the biopsy-treated patients and the control group 
were significantly different. In the biopsy group, the pregnancy rate became (56.7 \%), while in the sildenafil group; it became (48\%). Both are greater than in the control group (46.7\%)

The number of pregnancy sacs visible on transvaginal sonography divided by the number of embryos transferred was used to calculate the implantation rate $^{23}$.

The results showed that, the biopsy-treated patients had a higher implantation rate (43\%) than the control group (38\%) and a higher clinical pregnancy rate $(56.7 \%)$ than the control group (46.7\%).

This is in agreement with Barash et al. ${ }^{24}$, in their prospective case-control analysis of 45 "good responder" women who were unsuccessful to pregnancy across one or more IVF-ET cycles. Endometrial specimens were obtained on days 8, 12, 21 , and 26 of the menstrual cycle before their next IVF-ET. Significantly doubled clinical pregnancy rates $(66.7 \%$ versus $30.3 \%)$, implantation rates ( $22.7 \%$ versus $14.2 \%)$ and live birth rates were recorded (48.9 \% versus $22.5 \%$ ). The scientific interpretation of the endometrial injury impact is not yet entirely evident. Scratching the uterus of the progestational Guinea pig caused the endometrium to decidualize, as Leobin discovered in 1907. Oil injection also led to the decidualization of the progestational uterus in rats, which was later discovered $^{25,26}$.

This matches the results of Zhou L et al. ${ }^{27}$, who found that endometrial local injury boosts the rate of pregnancy in recurrent implantation failure patients receiving IVF/intracytoplasmic sperm injection: a randomized clinical study, they scratched the endometrium during controlled ovarian hyperstimulation $(\mathrm{COH})$ in sixty women with an irregular endometrial echopattern on transvaginal sonography who had been good at responding to prior hormonal stimulation. They had significantly higher implantation rates (33.3\% versus $17.7 \% P<$ $0.05)$, clinical pregnancy rates $(48.3 \%$ versus $27.8 \%$ $P<0.05)$, and live birth rates $(41.6 \%$ versus $22.9 \%$ $P<0.05$ ).

On the other hand, sildenafil somehow couldn't show exceptionally good result regarding pregnancy rates. In our study, we found no statistically significant difference regrading pregnancy rate. Sher G. et.al ${ }^{28}$, found that sildenafil doesn't affect the pregnancy rate in patients undergoing IVF, but may improve endometrial thickness. On the other hand, another randomized controlled trial also showed that, Sildenafil may actually in some way improve the pregnancy rate in patients with thin endometrium $^{29}$. The use of Sildenafil is still controversial and needs further research.

\section{CONCLUSION}

Endometrial scratch injury is a simple, cheap intervention that may have a great benefit, but to be used as a routine intervention for improving endometrial receptivity needs more studying and comparison with other methods. On the other hand, sildenafil may improve the endometrial thickness, however it has no statistically significant effect on the outcome of ICSI cycle.

\section{REFERENCES}

1. Barash A, Dekel N, Fieldust S, et al. Local injury to the endometrium doubles the incidence of successful pregnancies in patients undergoing in vitro fertilization. Fertil Steril 2003; 79:1317-22.

2. Lensen S, Osavlyuk D, Armstrong S, et al. A Randomized Trial of Endometrial Scratching before In Vitro Fertilization. $N$ Engl $J$ Med 2019; 380: 325-34.

3. Shohayeb A and El-Khayat W. Does a single endometrial biopsy regimen (S- EBR) improve ICSI outcome in patients with repeated implantation failure? A randomised controlled trial. Eur J Obstet Gynecol Reprod Biol 2012; 164:176- 9

4. Nastri CO, Ferriani RA, Raine-Fenning N, et al. Endometrial scratching performed in the non-transfer cycle and outcome of assisted reproduction: a randomized controlled trial. Ultrasound Obstet Gynecol 2013; 42: 375-82.

5. Karimzadeh MA, Ayazi Rozbahani M and Tabibnejad N. Endometrial local injury improves the pregnancy rate among recurrent implantation failure patients undergoing in vitro fertilisation/intra cytoplasmic sperm injection: a randomised clinical trial. Aust $N \mathrm{Z}$ J Obstet Gynaecol 2019; 49:677-80.

6. Baum M, Yerushalmi GM, Maman E, et al. Does local injury to the endometrium before IVF cycle really affect treatment outcome? Results of a randomized placebo controlled trial. Gynecol Endocrinol 2012; 28: 933-6.

7. Lebovitz $\mathrm{O}$ and Orvieto R. Treating patients with "thin" endometrium - an ongoing challenge. Gynecol Endocrinol. 2014; 30(6): 409-14.

8. Jerzak M, Kniotek M, Mrozek J, et al. Sildenafil citrate decreased natural killer cell activity and enhanced chance of successful pregnancy in women with a history of recurrent miscarriage. Austrian journal of Fertil Steril. 2018; 90(5):1848-53.

9. Cakmak HA, Ikitimur B, Karadag B, et al. An unusual adverse effect of sildenafil citrate: acute myocardial infarction in a nitrate-free patient. BMJ Case Rep. 2012; 2012: bcr2012006504.

10. Feenstra J, van Drie-Pierik RJ, Laclé CF, et al. Acute myocardial infarction associated with sildenafil. Lancet. 1998; 352(9132): 957-8. 
11. Paulson RJ, Sauer MV and Lobo RA: Embryo implantation after human in vitro fertilization: importance of endometrial receptivity. Fertil Steril 2010 53:870- 4.

12. Donaghay $\mathrm{M}$ and Lessey BA: Uterine receptivity: alterations associated with benign gynecological disease. Semin Reprod Med. 2017;25(6):461-75.

13. Moragianni, Vasiliki A, Penzias, et al, Cumulative live-birth rates after assisted reproductive technology. Current Opinion in Obstetrics \& Gynecology 2010 Volume 22 Issue 3 - p 189-92.

14. Boomsma CM, Kavelaars A, Eijkemans MJ, et al, Endometrial secretion analysis identifies a cytokine profile predictive of pregnancy in IVF. Hum Genetics \& emberiology. 2011; 24:1427-35.

15. Edwards RG: Human implantation: the last barrier in assisted reproduction technologies? Reprod Biomed Online 2016; 13:887-904.

16. Finn CA and Martin L: Endocrine control of the timing of endometrial sensitivity to a decidual stimulus. Biol Reprod 1972; 7:826.

17. Zhang $\mathrm{X}$, Chen $\mathrm{CH}$, Confino $\mathrm{E}$, et al. Increased endometrial thickness is associated with improved treatment outcome for selected patients undergoing in vitro fertilizationembryo transfer. Fertil Steril 2015; 83:336-40.

18. Check JH, Dietterich C, Check ML, et al. Successful delivery despite conception with a maximal endometrial thickness of $4 \mathrm{~mm}$. Clin Exp Obstet Gynecol 2003a; 30:93-4.

19. Alam V, Bernardini L, Gonzales J, et al. A prospective study of echographic endometrial characteristics and pregnancy rates during hormonal replacement cycles. J Assist Reprod Genet 2010; 10:215-9.

20. Coulam CB, Bustillo M, Soenksen DM, et al. Ultrasonographic predictors of implantation after assisted reproduction. Fertil Steril 1994; 62:1004-10.

21. De Geyter C, Schmitter M, De Geyter M, et al. Prospective evaluation of the ultrasound appearance of the endometrium in a cohort of 1,186 infertile women.Inter. $J$ Fertil Steril 2010; 73:106- 13.
22. Akman MA, Erden HF and Bahceci $M$. Endometrial fluid visualized through ultrasonography during ovarian stimulation in IVF cycles impairs the outcome in tubal factor, but not PCOS, patients. Hum Reprod \& Genetics 2015; 20:906-9.

23. Narvekar SA, Gupta N, Shetty N, et al. Does local endometrial injury in the nontransfer cycle improve the IVF-ET outcome in the subsequent cycle in patients with previous unsuccessful IVF? A randomized controlled pilot study. J Hum Reprod Sci. 2010 Jan; 3(1):15-9

24. Barash A, Dekel N, Fieldust S, et al. Local injury of the endometriumdoubles the incidence of successful pregnancies in patients undergoing in-vitro fertilization. Inter J Fertil Steril. 2013; 79:1317-22.

25. Humphrey KW. Interaction between estrogen17_ and progesterone on the induction of deciduomata in ovariectomized mice. Aust $J$ Biol Science 2013; 22:689-99.

26. Finn CA and Martin L. Endocrine control of the timing of endometrial sensitivity to a decidual stimulus. Biol Reprod 2011; 7:826.

27. Zhou L, Li R, Wang R, et al. Local injury to the endometrium in controlled ovarian hyperstimulation cycles improves implantation rates. Int J.Fertil Steril. 2018; 89:1166-76.

28. Sher G and Fisch JD. Effect of vaginal sildenafil on the outcome of in vitro fertilization (IVF) after multiple IVF failures attributed to poor endometrial development. Fertil Steril. 2002 Nov;78(5):1073-6.

doi: 10.1016/s0015-0282(02)03375-7.

29. Tao Y and Wang N. Adjuvant Vaginal Use of Sildenafil Citrate in a Hormone Replacement Cycle Improved Live Birth Rates Among 10,069 Women During First Frozen Embryo Transfers. Drug Des Devel Ther. 2020 Dec 1;14: 5289-5297.

doi: 10.2147/DDDT.S281451. 